\title{
Classification and occurrence of abnormally developed Paradiplozoon homoion (Monogenea, Diplozoinae) parasitising gudgeon Gobio gobio
}

\author{
M. Pečínková1,* ${ }^{1,}$ I. Matějusováa, ${ }^{1,2}$ B. Koubková ${ }^{1}$, M. Gelnar ${ }^{1}$ \\ ${ }^{1}$ Department of Zoology and Ecology, Faculty of Science, Masaryk University, Kotlářská 2, 61137 Brno, Czech Republic \\ ${ }^{2}$ FRS Marine Laboratory, PO Box 101, Victoria Road, Aberdeen AB11 9DB, UK
}

\begin{abstract}
Morphological analyses of the attachment apparatus (clamps and central hooks) of Paradiplozoon homoion (Bychowsky \& Nagibina, 1959) (Diplozoinae, Monogenea) parasitising gills of Gobio gobio (L.) showed a high percentage of abnormally developed parasite specimens. Four different localities in the Vlára River basin, Czech Republic, were investigated for the presence of such abnormal individuals. The highest percentage of abnormalities in the attachment apparatus (over $39 \%$ ) was recorded in the Vlára River, at Bohuslavice. This study provides a comprehensive classification of these abnormalities with 7 types of abnormalities described and illustrated. Abnormalities of parts of the attachment apparatus that form in the later stage of ontogenetic development were the most frequent, the most frequent types of abnormalities being clamps with abnormal sclerites, and combinations of abnormalities. Abnormalities of the central hooks were also found in our material. The abnormalities found in diplozoids are probably connected with environmental pollution; however, this point requires further investigation.
\end{abstract}

KEY WORDS: Paradiplozoon homoion · Monogenea · Abnormality · Attachment apparatus · Gobio gobio Resale or republication not permitted without written consent of the publisher

\section{INTRODUCTION}

Fish parasites are adapted to the specific conditions of both their abiotic aquatic environment and their hosts (Pietrock et al. 2001), making them potentially useful as important determinants of their hosts' health and excellent biological indicators of water contamination (Poulin 1992). The effect of environmental pollution such as quality of water and bottom sediment on monogenean parasites has been postulated by several authors (Koskivaara et al. 1991a,b, Gelnar et al. 1997, Dušek et al. 1998).

Diplozoids (Diplozoinae) are monogenean parasites living mainly on the gills of cyprinid fish. The life-cycle is direct, including a free-swimming oncomiracidium and parasitic larva known as a diporpa. Two larvae fuse in permanent cross copula and live as a pair in their adult life. The apparatus that maintains attach- ment of the adult diplozoids to the host consists of a pair of central hooks and 4 pairs of clamps on each haptor of the pair. The central hooks and 1 pair of clamps are present both in oncomiracidia which develop in the egg and in free-swimming oncomiracidia. During the diporpa stage 2, 3 or 4 pairs of clamps develop (Khotenovsky 1985). There are very few records of abnormally developed specimens of diplozoids showing abnormalities relating mainly to the attachment apparatus (Bovet 1967, Oliver \& Reichenbach-Klinke 1973, Kuperman 1992, Zharikova 1993, Šebelová et al. 2002). The abnormalities of the attachment apparatus of diplozoids were linked either to non-optimal living conditions or to the mutagenic effect of toxic substances from polluted waters (Kuperman 1992, Zharikova 1993, Šebelová et al. 2002). In laboratory conditions, abnormalities of the Diplozoon paradoxum attachment apparatus, such as absence of 
central hooks or clamps and clamp abnormalities, were recorded (Bovet 1967). As this experiment was designed to study the effect of water temperature on eggs during incubation, the author assumed that high temperatures (above $23^{\circ} \mathrm{C}$ ) during incubation of eggs were the cause of the abnormalities. Later on, abnormalities of the clamps were described for Paradiplozoon homoion, and a basic categorisation of abnormalities of the attachment apparatus was included (Oliver \& Reichenbach-Klinke 1973). A reduction in the number of the attachment clamps compared to normally developed specimens, together with asymmetry in the arrangement of the clamps, was also observed in $D$. paradoxum by Kuperman (1992). A 1:8 ratio of abnormally versus normally developed clamps was recorded. Zharikova (1993) also revealed asymmetry in the number of attachment clamps as well as changes in the body structure of $D$. paradoxum.

A comparative study, which included more than 1 species of diplozoid (Diplozoon paradoxum, Paradiplozoon ergensi, P. megan, P. homoion), was presented by Šebelová et al. (2002). Changes in the morphology and dimensions of the attachment clamps were categorised into 4 types: changes in the size of clamps without accompanying alternations in their structure, morphological alterations of the standard size of clamps, abnormalities involving the absence of some clamps, and combinations of these 3 types of morphological abnormalities. Although a limited number of specimens of each species was studied, $P$. homoion was stated as the species with the most abnormalities.

Abnormalities of the attachment apparatus were also registered in other oviparous monogeneans, for example Dactylogyrus wunderi (Dactylogyridea) (Zharikova 1993) or viviparous monogeneans such as Gyrodactylus pungitii (Gyrodactylidea) (Harris 1998). However, these are sporadic findings and the causes of the abnormalities only speculative.
The aim of this study was to report the occurrence of abnormalities of the attachment apparatus of Paradiplozoon homoion with particular focus on the categorisation of the different types of abnormalities.

\section{MATERIALS AND METHODS}

In total, 152 gudgeons Gobio gobio (L.) were collected from 4 localities along the Vlára River basin from November 2000 to October 2002 (Table 1). The distribution of the localities along the Vlára River basin is illustrated in Fig. 1. All Paradiplozoon homoion (Bychowsky \& Nagibina, 1959) specimens were removed from the gills, and the haptor of each of the specimens was cut off, fixed with a mixture of ammonium picrateglycerin (Malmberg 1956, Ergens 1969) and mounted on a microscope slide. Haptors of adults were stained in Gomori's trichrome stain solution, prepared according to Humason (1967). The morphology of the clamps and central hooks was studied using a light microscope equipped with differential interference contrast (Nomarski DIC) and phase contrast, and was compared with a standard of normally developed sclerites (see Figs. 2 \& 3). A parasite with an abnormal clamp or central hook compared to the normally developed structure was categorised as an abnormal diplozoid.

Parasite mean intensity of infection, abundance and prevalence were calculated according to Bush et al. (1997).

\section{RESULTS}

A total of 463 specimens of Paradiplozoon homoion were recovered from gills of gudgeons at 4 localities along the Vlára River basin (see Fig. 1). Epidemiological characteristics such as mean intensity of infection, abundance and prevalence are recorded in

Table 1. Sampling localities with details of Gobio gobio collected and epidemiological characteristics of Paradiplozoon homoion infection

\begin{tabular}{|c|c|c|c|c|c|c|c|c|}
\hline Locality & $\begin{array}{l}\text { Date of } \\
\text { collections }\end{array}$ & $\begin{array}{l}\text { No. of } \\
\text { G. gobio }\end{array}$ & $\begin{array}{l}\text { Weight of } \\
\text { fish (g) } \\
\text { Mean (range) }\end{array}$ & $\begin{array}{l}\text { Standard length } \\
\text { of fish }(\mathrm{cm}) \\
\text { Mean (range) }\end{array}$ & $\begin{array}{l}\text { No. of } \\
\text { P. homoion } \\
\text { collected }\end{array}$ & $\begin{array}{l}\text { Intensity of } \\
\text { infection } \\
\text { Mean (range) }\end{array}$ & Abundance & $\begin{array}{c}\text { Prevalence } \\
(\%)\end{array}$ \\
\hline \multirow{3}{*}{$\begin{array}{l}\text { Vlára River, } \\
\text { Svatý Štěpán }\end{array}$} & November 2000 & 13 & $21.18(4.9-36.0)$ & $10.65(7.1-12.8)$ & 34 & $3.40(1-9)$ & 2.62 & 76.92 \\
\hline & April 2001 & 15 & $22.97(5.1-47.5)$ & $10.43(7.0-13.5)$ & 52 & $4.73(2-10)$ & 3.47 & 73.33 \\
\hline & October 2001 & 15 & $9.59(2.1-29.8)$ & $7.93(4.8-12.2)$ & 35 & $3.89(1-9)$ & 2.33 & 60.00 \\
\hline \multirow{3}{*}{$\begin{array}{l}\text { Vlára River, } \\
\text { Bohuslavice }\end{array}$} & April 2001 & 15 & $8.19(2.6-21.6)$ & $7.59(5.5-10.4)$ & 46 & $3.83(1-16)$ & 3.07 & 80.00 \\
\hline & October 2001 & 15 & $8.37(4.6-19.4)$ & $7.99(6.2-10.8)$ & 40 & $3.64(1-7)$ & 2.67 & 73.33 \\
\hline & October 2002 & 20 & $15.38(2.6-28.0)$ & $9.76(6.0-12.3)$ & 87 & $4.83(1-10)$ & 4.35 & 90.00 \\
\hline \multirow{2}{*}{$\begin{array}{l}\text { Ř́ka River, } \\
\text { engineering plant }\end{array}$} & October 2001 & 15 & $16.11(8.5-33.1)$ & $9.72(7.7-12.4)$ & 83 & $5.93(2-13)$ & 5.53 & 93.33 \\
\hline & April 2002 & 24 & $13.76(3.3-30.7)$ & $8.79(5.6-12.0)$ & 45 & $3.00(1-12)$ & 1.88 & 62.50 \\
\hline Říka River, Slavičín & October 2002 & 20 & $25.02(14.8-37.5)$ & $11.34(9.3-13.3)$ & 41 & $2.41(1-6)$ & 2.05 & 85.00 \\
\hline
\end{tabular}



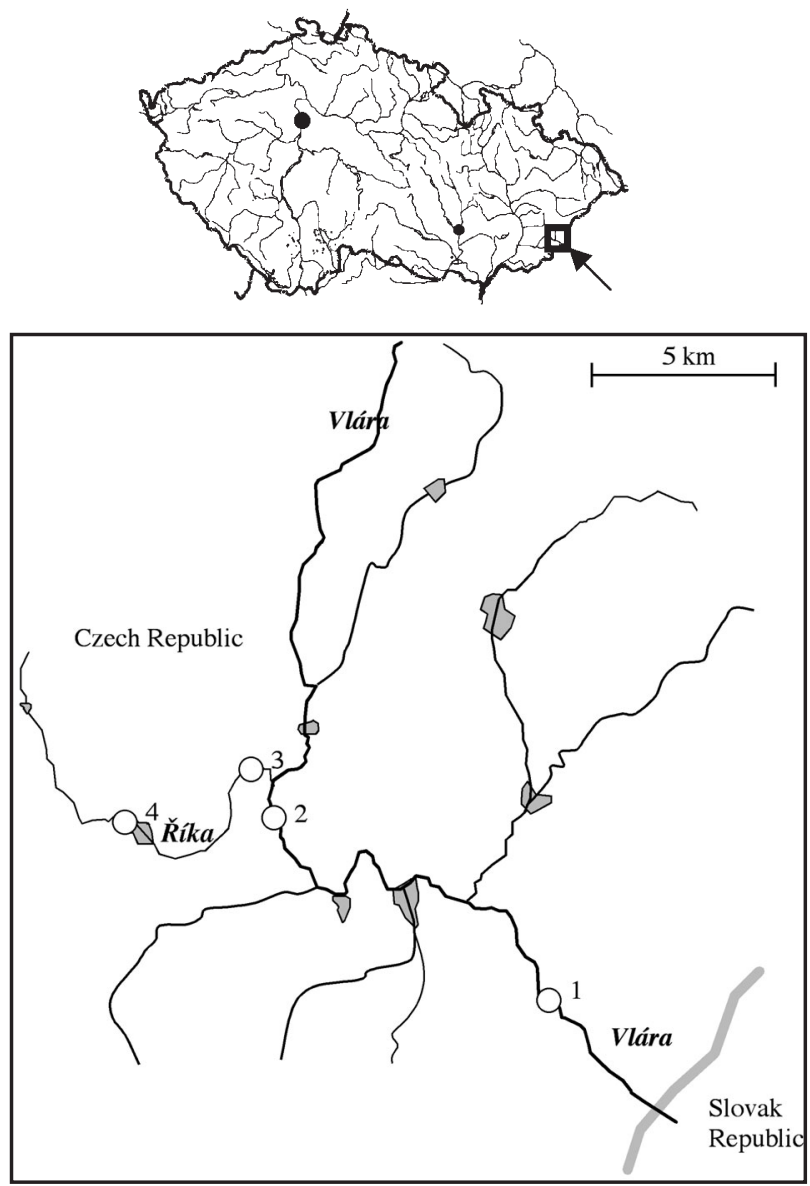

Fig. 1. Map of the Vlára River basin, Czech Republic, with the studied localities marked: 1: Vlára River, Svatý Štěpán; 2: Vlára River, Bohuslavice; 3: Ríka River, engineering plant; 4: Ríka River, Slavičín

Table 1. Parasites were collected during spring and autumn to maximise collection of parasites in the adult stage of development, as these were used to analyse the percentage of abnormally developed specimens (Table 2).

Table 2. Occurrence of Paradiplozoon homoion with abnormalities

\begin{tabular}{|llcc|}
\hline Locality & $\begin{array}{l}\text { Date of } \\
\text { collections }\end{array}$ & $\begin{array}{c}\text { No. of } \\
\text { P. homoion }\end{array}$ & $\begin{array}{c}\text { No. of abnormal } \\
\text { P. homoion (\%) }\end{array}$ \\
\hline Vlára River, & November 2000 & 34 & $12(35.29)$ \\
Svatý Štépán & April 2001 & 52 & $15(28.85)$ \\
& October 2001 & 35 & $7(20.00)$ \\
Vlára River, & April 2001 & 46 & $18(39.13)$ \\
Bohuslavice & October 2001 & 40 & $11(27.50)$ \\
& October 2002 & 87 & $28(32.18)$ \\
Ř́ka River, & October 2001 & 83 & $30(36.14)$ \\
engineering plant & April 2002 & 45 & $10(22.22)$ \\
Ř́ka River, Slavičín & October 2002 & 41 & $12(29.27)$ \\
Total & & 463 & $143(30.89)$ \\
\hline
\end{tabular}

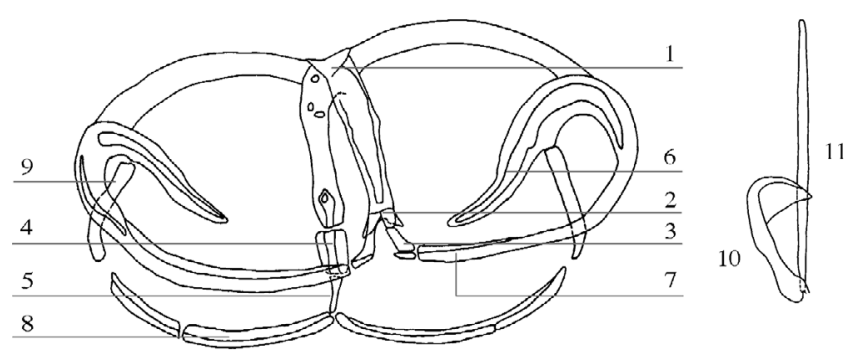

Fig. 2. Paradiplozoon homoion. Morphology of the normally developed attachment clamp and central hook of adult diplozoid. 1: median plate; 2: trapeze spur; 3 : anterior joining sclerites of the median plate; 4 : sclerites of the proximal tip of the median plate; 5 : sclerites of the distal tip of the median plate; 6: spiky spur; 7: anterior jaw; 8: medial sclerite of the posterior jaw; 9: lateral sclerite of the posterior jaw; 10: body of the central hook; 11: handle of the central hook

More than $30 \%$ of parasites from 4 localities had abnormalities of the attachment apparatus. The percentage of abnormal specimens during the study period is recorded in Table 2. Abnormally developed diplozoid specimens were found at the Bohuslavice locality (39.13\%) in April 2001. During additional (October 2001, October 2002) collections of diplozoids at this locality, the percentage of abnormal diplozoids was lower, but always reached over $27 \%$ (Table 2 ). In October 2001, diplozoids were collected from 3 localities (Vlára River: Svatý Štěpán, Bohuslavice; Ríka River: engineering plant). The greatest prevalence of abnormalities was found on parasites collected from the Říka River and in the direction of the Vlára River flow the number of diplozoids with abnormalities decreased.

All abnormalities of attachment apparatus recorded were categorised into 7 types. Some of these abnormalities have already been discussed in the literature (Bovet 1967, Oliver \& Reichenbach-Klinke 1973, Kuperman 1992, Zharikova 1993, Šebelová et al. 2002), but new types of clamp abnormalities and rare abnormalities of the central hooks were also detected. The types of abnormalities found were as follows: (1) size reduction of adult parasite clamps without changes in their sclerite structure (Fig. 9); (2) clamps with abnormal sclerites: absence or reduction of sclerites, additional sclerites (Fig. 7), or misshapen sclerites (Fig. 6); (3) rudimentary clamps (Figs. 10 \& 11); (4) absence of some clamps (Fig. 8); (5) additional clamp or pair of clamps: additional rudimentary clamp (Fig. 11) or additional type 2 clamp (Fig. 12); (6) a combination of abnormalities 


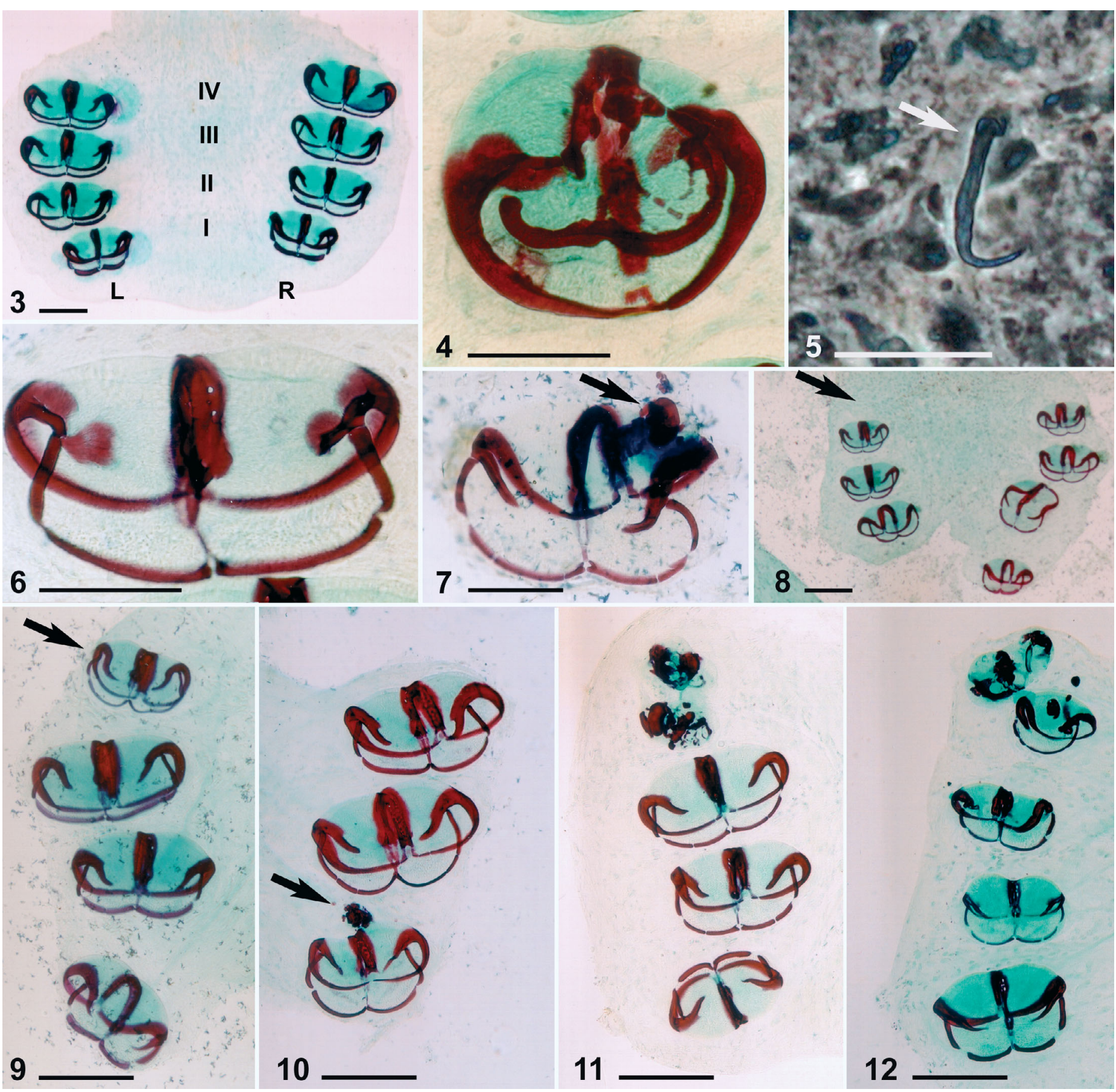

Figs. 3 to 12. Paradiplozoon homoion. Fig. 3. Haptor with clamps and their layout ( $\mathrm{L}=$ left, $\mathrm{R}=$ right, I-IV = clamps of first to fourth pair). Scale bar $=100 \mu \mathrm{m}$. Nomarski DIC. Fig. 4. Clamp with size reduction and misshaped median plate and spiky spur, without dividing of posterior jaws into medial and lateral sclerites and with presence of additional sclerites (Type 6). Scale bar $=50 \mu \mathrm{m}$. Nomarski DIC. Fig. 5. Absence of the handle of the central hook (Type 7) (arrow). Scale bar $=20 \mu \mathrm{m}$. Phase contrast. Fig. 6. Misshaped structure of spiky spurs (Type 2). Scale bar $=50 \mu \mathrm{m}$. Nomarski DIC. Fig. 7. Spiky spur and median plate connected by additional sclerite (Type 2) (arrow). Scale bar $=50 \mu \mathrm{m}$. Nomarski DIC. Fig. 8. Absence of 1 left clamp (Type 4) (arrow). Scale bar $=100 \mu$ m. Nomarski DIC. Fig. 9. Fourth clamp of adult parasite with size reduction (Type 1) (arrow). Scale bar $=100 \mu \mathrm{m}$. Nomarski DIC. Fig. 10. Rudimentary second pair clamp (Type 3) (arrow). Scale bar $=100 \mu \mathrm{m}$. Nomarski DIC. Fig. 11. Fourth and additional (fifth) rudimentary clamps (Types 3 and 5). Scale bar $=100 \mu \mathrm{m}$. Nomarski DIC. Fig. 12. Fourth clamp with combination of abnormalities (Type 6) and additional (fifth) clamp with abnormal sclerities (Type 5). Scale bar $=100 \mu \mathrm{m}$. Nomarski DIC 


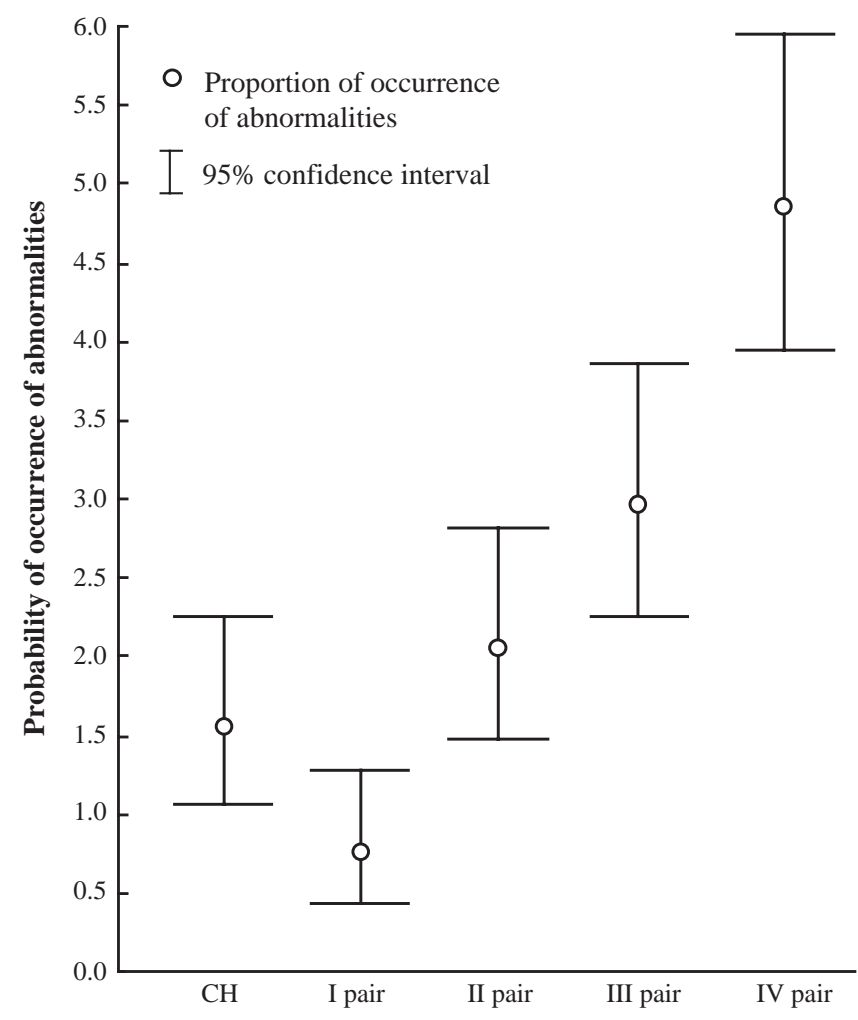

Fig. 13. Paradiplozoon homoion. Confidence intervals for the probability of the occurrence of abnormal clamps or central hooks $(\mathrm{CH}=$ central hooks; I, II, III, IV pair = pairs of diplozoid attachment clamps)

(Figs. 4 \& 12); (7) abnormalities of the central hooks: absence or reduction of the handle of the central hook (Fig. 5), absence or reduction of the body of the central hook or absence of the central hook.

The most frequent types of abnormalities were clamps with abnormal sclerites (Type 2) $(27.66 \%)$ and combinations of abnormalities (Type 6) (33.19\%). Moreover, the greatest proportion of abnormalities was found on the fourth pair of clamps (39.82\%) ( $p<$ 0.05; chi-square with Yates correction) (Fig. 13). There were only a few cases where the first pairs of clamps were abnormally developed $(6.19 \%)$ ( $p<0.05$; chisquare with Yates correction).

\section{DISCUSSION}

Causes of the abnormally developed attachment apparatus and possible effects of this on the attachment of diplozoids to the host gills are so far unresolved. The majority of authors dealing with this problem discussed environmental pollution as the main cause (Bovet 1967 , Kuperman 1992, Zharikova 1993, Šebelová et al. 2002).

In our study, a relatively large number of diplozoids displayed abnormalities (about 30\% of all examined adult diplozoids). Šebelová et al. (2002) found abnormalities present in only 9 individuals from 132 specimens of 3 species of Paradiplozoon from chub Leuciscus cephalus examined, and $12 \%$ of Diplozoon paradoxum recovered from bream Abramis brama exhibited some type of clamp abnormality.

The presence of rudimentary clamps (Type 3 abnormality) (8.94\%) has not previously been recorded. Abnormalities of the central hook (Type 7) (12.34\%) were previously observed only by Bovet (1967) on diplozoids from Abramis brama. The most frequent abnormality mentioned by almost all authors was the absence of some of the clamps (Bovet 1967, Oliver \& Reichenbach-Klinke 1973, Kuperman 1992, Zharikova 1993, Šebelová et al. 2002). This is probably due to the fact that the absence of whole attachment clamps is the most visible and obvious abnormality. Unfortunately, apart from Šebelová et al. (2002), authors have not stated the frequency of occurrence of these abnormalities. Of all abnormally developed specimens of Diplozoon paradoxum found by Šebelová et al. (2002), 55 \% were seen to have a reduced number and arrangement (4:4) of clamps (Type 4); $10 \%$ of abnormal D. paradoxum showed complete reduction of the clamp on 1 side of the haptor, arrangement 4:0 (Type 4); and $35 \%$ abnormal D. paradoxum had deformed clamps that were smaller than normal.

Abnormalities were most frequently found on the fourth pair of clamps $(39.82 \%)$ that start to form in the latest stage of diplozoid ontogenetic development $(\mathrm{p}<$ 0.05; chi-square with Yates correction) (Fig. 13). In contrast to our findings, Šebelová et al. (2002) recorded that in most cases clamps of the second and third pairs were damaged or deformed.

Finally, we suggest that a large number of abnormalities found in diplozoids may be caused by environmental pollution. However, this requires further study and the subject of future research will be to determine concentrations of polychlorinated biphenyls, polycyclic aromatic hydrocarbons and heavy metals in river sediments and muscle tissues of individual fish and in situ bioindication of the adverse effects of pollutants. We would also like to perform tests comparing reproducibility of abnormally and normally developed specimens.

Acknowledgements. We would like to thank A. Žáček and other officials and managers of the Moravian Angling Club of Slavičín, who enabled us to carry out this research on their river system. We also thank Dr. P. Jurajda, Institute of Vertebrate Biology, Brno, Czech Republic for electrofishing. The project was supported by The Grant Agency of the Czech Republic (Project No. 524/04/1115 to M.P. and B.K.), The Research Project of the Masaryk University (No. MSM 0021622416). I.M. was funded by an EC Marie Curie Individual Fellowship QLK5-CT-2001-51038. We would also like to thank Dr. Carey O. Cunningham for the English correction of the manuscript. 


\section{LITERATURE CITED}

Bovet $\mathrm{J}$ (1967) Contribution à morphologie et à la biologie de Diplozoon paradoxum v. Nordmann, 1832. Bull Soc Neuchateloise Sci 3:64-159

Bush AO, Lafferty KD, Lotz JM, Shostak AW (1997) Parasitology meets ecology on its own terms: Margolis et al. revisited. J Parasitol 83:575-583

Dušek L, Gelnar M, Šebelová Š (1998) Biodiversity of parasites in a freshwater environment with respect to pollution: metazoan parasites of chub (Leuciscus cephalus L.) as a model for statistical evaluation. Int J Parasitol 28: $1555-1571$

Ergens R (1969) The suitability of ammonium picrate-glycerin in preparing slides of lower Monogenoidea. Folia Parasitol 16:320

Gelnar M, Šebelová Š, Dušek L, Koubková B, Jurajda P, Zahrádková S (1997) Biodiversity of parasites in freshwater environment in relation to pollution. Parassitologia 39:189-199

Harris PD (1998) Extreme morphological variation between related individuals of Gyrodactylus pungitii Malmberg, 1964 (Monogenea). Syst Parasitol 39:137-140

Humason GL (1967) Animal tissue techniques. WH Freeman, San Francisco, CA

Khotenovsky IA (1985) Fauna of the USSR: Monogenea. Suborder Octomacrinae Khotenovsky. Nauka, Leningrad (in Russian)

Editorial responsibility: Wolfgang Körting,

Hannover, Germany
Koskivaara M, Valtonen ET, Prost M (1991a) Dactylogyrids on the gills of roach in Central Finland: features of infection and species composition. Int J Parasitol 21:565-572

Koskivaara M, Valtonen ET, Prost M (1991b) Seasonal occurrence of gyrodactylid monogeneans on the roach (Rutilus rutilus) and variations between four lakes of differing water quality in Finland. Aqua Fenn 21:47-55

Kuperman BI (1992) Parasites as bioindicators of the pollution of water bodies. Parazitologiya 26:479-482 (in Russian)

Malmberg G (1956) On the occurrence of Gyrodactylus on Swedish fishes. In: Skrifterutgivna av Södra Sveriges Fiskeriformening Årsskr 34:20-75 (in Swedish)

Oliver G, Reichenbach-Klinke HH (1973) Observations sur le genre Diplozoon von Nordmann, 1832 en LanguedocRousillon. Ann Parasit Hum Comp 48:447-456

Pietrock M, Meinelt T, Marcogliese DJ, Steinberg CEW (2001) Influence of aqueous sediment extracts from the Oder River (Germany/Poland) on survival of Diplostomum sp. (Trematoda: Diplostomidae) cercariae. Arch Environ Contam Toxicol 40:327-332

Poulin R (1992) Toxic pollution and parasitism in freshwater fish. Parasitol Today 8:58-61

Šebelová Š, Kuperman B, Gelnar M (2002) Abnormalities of the attachment clamps of representatives of the family Diplozoidae. J Helminthol 76:249-259

Zharikova TI (1993) Influence of anthropogenic pollution of waters on ectoparasites of bream, Abramis brama. Zool Zh 72:73-83 (in Russian)

Submitted: March 15, 2004; Accepted: August 9, 2004

Proofs received from author(s): February 25, 2005 